\title{
O canto de Caetano da Costa Alegre no contexto do final do séc. XIX em Portugal
}

\section{Caetano da Costa Alegre's poetry at the end of the 19th century in Portugal}

Naduska Mário Palmeira ${ }^{\prime}$

DOI: 10.11606/issn.1981-7169.crioula.2017.137532

RESUMO: O objetivo deste trabalho é o de situar a poesia de Caetano da Costa Alegre, poeta são-tomense, no contexto das literaturas produzidas em Portugal e na Europa no final do século XIX. Além de analisar as condições sócio-culturais e afetivas no espaço de enunciação do autor. Como base teórica, as reflexões de Eça de Queiroz acerca da Europa e da imagem que se fazia do homem africano à época são uma chave para a análise da obra do poeta das ilhas, muitas vezes caracterizado como poeta da "cor dolorosa".

ABSTRACT: The aim of this work is to situate the poetry of Author, a São-Toméan poet, in the context of literatures produced in Portugal and Europe at the end of the 19th century, as well as to analyze the socio-cultural and affective conditions in the space of enunciation of the author. As a theoretical basis, Eça de Queiroz's reflections on Europe and the image of the African man at the time are a key to the analysis of the work of the island poet, often characterized as the poet of "painful color".

1 Doutoranda, UFRJ, desenvolve a pesquisa "A poética de Conceição Lima: reescrita de identidades ou a Casa a desvendar" 
PALAVRAS-CHAVE: Caetano da Costa Alegre; Eça de Queiroz; Literatura Portuguesa; Interdição afetiva e social; Poesia são-tomense.

KEYWORDS: Caetano da Costa Alegre; Eça de Queiroz; Portuguese literature; Afective and social interdition; São-thomean poetry.

\section{Caetano da Costa Alegre e seu tempo}

"Este fim de século é um fim de mundo"

(Eça de Queiroz)

« $\mathrm{m}$ sua História da Literatura Portuguesa (1996), António José Saraiva afirma ser a época romântica um todo que La engloba diversas manifestações a que outros autores conferem estatuto diferenciado. Saraiva percebe no Romantismo, por certo, a grande ruptura com a época clássica, pela ascensão da individualidade, como consequência, da expressão das emoções, e daquilo que a marcaria, a originalidade, fosse ela autoral ou marca de um povo.

Dessa forma, as manifestações parnasianas, simbolistas e as que a maioria dos estudiosos cunha como "Escola Realista" estariam ao abrigo do grande conceito romântico, que merecerá diferenciação com o advento dos movimentos modernistas, reinterpretando, enfim, os princípios da grande escola de ruptura com o Clássico.

Eça de Queiroz afirma, em seu ensaio "Positivismo e Idealismo", acerca do final do século XIX que 
Em literatura, estamos assistindo ao descrédito do naturalismo. O romance experimental, de observação positiva, todo estabelecido em documentos, findou (se é que jamais existiu, a não ser em teoria) e o próprio mestre do naturalismo, Zola, é cada dia mais épico, à velha maneira de Homero. A simpatia, o favor, vão todos para o romance de imaginação, de psicologia sentimental ou humorista, de ressurreição arqueológica (e pré-histórica!) e até de capa e espada, como maravilhosos embróglios, como nos robustos tempos de D'Artagnan. (s/d: 1496)

Tal contextualização histórico-literária vem ao encontro de uma proposta à apreciação da obra de Caetano da Costa Alegre (1860-1894), o primeiro escritor nascido em São Tomé e Príncipe com presença efetiva nas letras europeias. Designado "romântico tardio" ou ultrarromântico por críticos das literaturas africanas de expressão portuguesa, Costa Alegre define-se, mais provavelmente, pelo anseio de integração social e cultural, por meio da arte, advindo da consciência da segregação racial que um emigrado sentiria no final do século XIX.

Para fins de contextualização e caracterização da obra de Costa Alegre, pode-se observar que nele convergem traços do romantismo byroniano - tanto pela referência ao fúnebre como pelos cantares de um spleen reduzido à não-realização amorosa -, do materialismo presente na obra de Antero de Quental, do apelo baudelairiano ao mórbido mesclado a um certo viés naturalista - talvez pela sua relação com a medici$\mathrm{na}^{2}$. Convergem, ademais, em suas letras, um diálogo com o cânone literário romântico da época, sua posição de homem

2 Caetano da Costa Alegre mudou-se para Lisboa em 1882, onde ingressou em um curso de Medicina, porém não o concluiu, pois morreu em 1890. 
negro, de margem, numa sociedade colonial, imperialista, e a tentativa de, por meio da linguagem poética, elaborar seus afetos tanto no que concerne ao plano pessoal, quanto no que diz respeito à relação com a própria cor. Há, pois, uma tentativa de reinterpretação da felicidade, tendo a linguagem literária como chão, suporte.

Afinal, é o Romantismo, mesmo após o seu suposto final, que perpassa as grandes obras brasileiras e portuguesas à época de Costa Alegre, que, assim como os grandes autores ditos realistas e simbolistas, segue o caminho aberto por aquela escola.

Tal influxo romântico em Costa Alegre, aliás, pode ser notado inclusive por fontes brasileiras, como Castro Alves (18471871), o "Poeta dos escravos", que logrou reconhecimento e êxito - até hoje - nas culturas de língua portuguesa. Tome-se como exemplo "O sonho dantesco", dedicado "À Ex.ma Sra. D. Cacilda Eirado Martins", uma brasileira, poema em que Costa Alegre cita um verso do "Navio negreiro", construindo cenário de alta sensibilidade, ao por em contraponto o distanciamento social da dama burguesa, portuguesa, que lê um texto de crítica e denúncia social, sem, no entanto, compreendê-lo:

\section{(...) Que estranha criancice! que loucura! \\ Como podia aquela mente pura Compreender o sonho gigantesco?!}

Contudo pensativa ela cismava, Imaginar o sonho procurava, Dizendo sempre: "Era um sonho dantesco"!... 
Ainda acerca dos influxos das escolas literárias de referência no séc. XIX em Costa Alegre, pode-se observar um sutil diálogo com a escola árcade, notadamente em certas idealizações platônicas do amor. Nele, o tópico do interdito amoroso, ou sua irrealização, é construído por meio da utilização de recursos antitéticos ou paradoxais, caros à escola árcade limítrofe às tardias manifestações barrocas.

\section{A (IM)POSSIBILIDADE DO RISO}

"Eu penso que o riso acabou - porque a humanidade entristeceu. E entristeceu - por causa da sua imensa civilização. O único homem sobre a Terra que ainda solta a feliz risada é o negro, na África. Quanto mais uma sociedade é culta, mais sua face é triste. (...)" (Eça de Queiroz, grifo meu)

A temática do amor platônico parece em Costa Alegre uma base ou estratégia literária para explicar ou explorar um determinado estado de espírito: a tentativa de elaborar sua emoções num espaço de interdição "racial", logo, social. Nele incide o interdito ao pleno gozo das aspirações amorosas, talvez mais pela falta de correspondência do que pela interdição decorrente da cor da pele, como sugeriram os autores dos textos da época, que anunciaram a morte do escritor em 1890, e por críticos que, até os dias de hoje, o consagraram como o poeta da "cor dolorosa". Na introdução à Breve história da felicidade na expressão contemporânea, Ronaldo Lima Lins questiona-se, 
Mas como recuperar no cotidiano, no miserável espaço em que nossas esperanças se banalizam, em que nos contemos para não avançar, o conteúdo de nossa interioridade muitas vezes dilacerada? Como recuperar nesse território por definição escorregadio e mistificador, no qual as lágrimas sugerem fraqueza ou perturbação emocional, as pistas que os indícios oferecem? O burburinho efervescente que nos cerca, indiscernível em seu gigantismo, retirado de seu timbre anônimo, sussurra nas frases ou palavras como um monólogo interior que, na esfera literária, os escritores decifram (...) (LINS, 1994: 14)

Posso afirmar que Costa Alegre decifra este monólogo interior em vários momentos de sua poética, de que destaco um poema, dedicado a Antero de Quental, em que o eu lírico é chamado a abrir os olhos da Razão para ver "o Deus por ele imaginado", Deus este que pode ser a representação de uma esperança, de um olhar constante para seu interior, ou, simplesmente, o desejo da imanência.

No prefácio à edição dos Versos de 1994, da Imprensa Nacional/Casa da Moeda, Lisboa, Francisco Soares empreende exaustivo estudo da obra de Costa Alegre. O estudioso procura, entre outras análises de cunho formal, desestigmatizar a imagem que Cruz Magalhães, autor de "Saudade", texto datado de 1890, constrói, em elogio póstumo, ao amigo e poeta. O mérito de Cruz Magalhães, sem dúvida, foi ter reunido, em 1916, toda a obra do escritor. Ele deixa marcada, todavia, a ideia de que Costa Alegre era um jovem infeliz e retraído, por conta da "suprema injustiça de ser negro".

Embora Cruz Magalhães sugerisse que "ser negro" era incompatível com o "Bem e [a] Justiça" - por que Costa Ale- 
gre ansiaria de forma "irresistível" -, o trabalho linguístico do poeta não confirma tal antítese. Ainda assim, os temas de sua poesia podem acender uma discussão acerca da dicotomia negro versus branco, perpassada por um sentimento resultante das discriminações sofridas pelo poeta, que não redunda, contudo, num calar-se ou inferiorizar-se pelo fato de o poeta ser um homem negro.

Aludindo à epígrafe de Eça de Queiroz nesta seção, que retomo,

Eu penso que o riso acabou - porque a humanidade entristeceu. E entristeceu - por causa da sua imensa civilização. O único homem sobre a Terra que ainda solta a feliz risada é o negro, na África. Quanto mais uma sociedade é culta, mais sua face é triste.

é importante ressaltar a visão que o escritor português parecia ter da África: não menos exótica que sorridente, tão elementar quanto ligada aos valores de sua época, marcada pelo imperialismo. Só estando na África é possível sorrir primitivamente. Ao contrastar a sociedade culta - triste e a África - alegre, feliz, Eça traça o perfil ideológico que se fazia do continente à sua época. "Os homens de ação e pensamento, hoje, estão implacavelmente, voltados à melancolia." (QUEIROZ, s/d: 1479).

Assim, pode-se ler, cuidadosamente, o ensaio de Eça de Queiroz, "A decadência do riso" (1891), e concluir que, porque está na Europa e deseja ser parte de uma pequena burguesia intelectual e financeira, Costa Alegre passa a pensar acer- 
ca das "tantas complicações da existência social que a ação, por meio do esforço que reclama, se tornou uma dor grande." (idem, ibidem).

É, pois, tênue o fio que separa as afirmações de Eça, provavelmente frutos de uma visão de época embaçada pelo colonialismo, da "verdade" histórica e social que elas guardam acerca daquilo que o Ocidente pensava sobre o africano em geral, vivendo na África: a criação mental de um continente marcado pelo exotismo, onde os homens, se soltam "a feliz risada primitiva", estão em contraposição ao homem que vive em uma sociedade culta que, logo, pensa. Eis que Costa Alegre desloca-se do lugar paradisíaco e feliz para a metrópole colonial: o riso teria dado lugar à melancolia devido ao desenraizamento de sua terra?; Ou as opressões sociais, econômicas e raciais fizeram do poeta um homem "de pensamento"triste?; Como se colocar a delicada questão diante da obra - curta e, aparentemente, inacabada - do poeta são-tomense?

Não é apenas o fato de ser negro ou de, no Ocidente, ter-se lugar para o pensamento, como afirma Eça, que se tece a melancólica e irônica obra de Costa Alegre, mas, muito mais evidente, o fato de locomover-se num ambiente que desprezava o lastro social e afetivo em que se constroem os Versos. A falta do devido reconhecimento pleno ao cidadão e ao poeta - ainda que iniciante nas artes das letras - o marca com a infeliz designação do "homem negro de alma branca". Sabe-se que a flexibilidade não é característica de uma metrópole colonial, o que me faz aludir ao que afirma Lins (1993): não é possível, em uma sociedade em que prevalece a rigidez em contraposição à flexibilidade, 
que o "outro" seja plenamente (re)conhecido, mas sim, o que se tem é a negação da alteridade. Entretanto, os Versos não corroboram a imagem do negro injustiçado, que tanto marcam - exageradamente - Costa Alegre como "o poeta da cor dolorosa". Trata-se aqui, muito mais, de algo que se liga ao sentimento de um homem "exilado", que viveu, ao contrário de Francisco José Tenreiro ${ }^{3}$, a maior parte de seus anos (de 1864 a 1883) em São Tomé - o que o fez sentir ainda mais estrangeiro ou estranho na metrópole colonial que não o acolhe, decerto, como um cidadão comum.

A vivência em São Tomé e a referência afetiva que Costa Alegre guardava das relações sociais são, em Lisboa, conjugadas ao preconceito racial, motivos óbvios e fortes para sua desilusão. Não se pode, todavia, interpretar superficialmente sua poesia reduzindo-a a sua dor pessoal, pois em sua arte de poeta iniciante se plasma algo maior: o sentimento de não-pertencimento e de interdição aos prazeres de um jovem de sua época. Isso o marca como um poeta ainda próximo aos valores que herdou de sua terra e os transplantou consigo para a Lisboa do final do século XIX. A poesia desse exilado é, portanto, essencial para a compreensão histórica da arte e da cultura de São Tomé e Príncipe. Segundo Lins, o que se pode aplicar à leitura da poesia de Costa Alegre:

\section{(...) A valorização do subjetivismo, uma das marcas da modernidade, ocorreu em consequência de uma}

3 Nascido em São Tomé e Príncipe em 1921. Tenreiro foi levado para Lisboa com dois anos de idade e lá morreu, em 1961. Poeta e geógrafo, Tenreiro é autor do livro de poemas llha de nome santo, publicado em 1942, considerada a primeira obra de caráter negritudinista escrita em língua portuguesa. 
angústia proveniente de fora, isto é, de nossa incapacidade em nos realizar dentro das condições objetivas... (LINS, 1993: 35)

Jovem em um ambiente de cultura artística pulsante é provável que Costa Alegre tenha embasado tal sentimento de exílio sobre as manifestações poéticas movediças e convergentes no Portugal dos fins do século XIX, em que vicejava ainda o que muitos críticos chamam de romantismo egótico, em que antíteses como amor versus morte, dúvida versus ironia, entusiasmo versus tédio são bastante cultivadas. Muitas vezes, Alfredo Bosi bem sintetizou como "auto-ironia masoquista" - nítida, por exemplo, na ousadia de versos como os de "Eu e os passeantes".

\section{Passa uma inglesa, \\ E logo acode, \\ Toda surpresa: \\ What a black, my God!}

Se é espanhola,
A que me viu,
Diz como rola:
Que alto, Dios mio!
$E$, se é francesa:
Ó quel beau nègre!
Rindo pra mim. 
Se é portuguesa,

Ó Costa Alegre!

Tens um atchim!.

(COSTA ALEGRE, 2012: 20)

Em tal poema, o sujeito poético, ciente de sua condição de negro e colonizado, coloca em contraste a reação de muIheres inglesas, francesas ou espanholas diante do homem africano - que o saúdam de maneira galanteadora ("What black my God!//(...) Que alto, Dios mio!//(...) Ó quel beau nègre!") - e a da portuguesa - que é a expressão de um mundo que o rejeita ("Ó Costa Alegre/Tens um atchim!").

A repulsa - vazada em auto-ironia ousada para os moldes românticos -, representada pelo "atchim", sintetiza a situação sociocultural adversa vivida pelo poeta, ao mesmo tempo em que critica a mentalidade vigente à época, colonial e racista.

Em contraste à tão sublinhada "cor dolorosa", a consciência do próprio valor, beleza física e humanidade - marcada pelas falas das mulheres francesa, inglesa e espanhola - não expõe uma dor, como por muito tempo sugerida e endossada pelos primeiros estudos sobre sua obra, que ainda fazem eco. Ao contrário, o sujeito poético, ressaltando a beleza do negro e a admiração das damas desprovidas do preconceito, personificado na mulher portuguesa, expõe e critica - com o pretexto e artifício artístico do microcosmo feminino - o desprezo, da maior parte da sociedade portuguesa da época, aos negros.

Os poemas em que Costa Alegre trabalha com a dicotomia das cores negra e branca, num tom angustiado, exprime, 
no mais das vezes, a dor de não ser amado, o que faz nascer a antítese "cor negra - luto e pena/raça branca - cheia de graça", como se pode observar no poema, cujo título, de per si, coloca-nos em dúvida ou em confronto com as agruras sociais por que passava o poeta.
A minha cor é negra
Indica luto e pena;
É luz, que nos alegra,
A tua cor morena.
É negra a minha raça,
A tua raça é branca,
Tu és cheia de graça,
Tens a alegria franca,
Que brota a flux do peito
Das cândidas crianças (...)

(idem, 2012: 31)

Trata-se de um poema de amor, um amor não correspondido, e, por isso, o sujeito poético, usando o artifício ou a estratégia da cor/raça, diz-se sucumbido, sem esperança. Seu "olhar atesta/que é triste o (seu) sonhar"; a luz divina que o ilumina pode ser a manhã, a que o sujeito poético irmana à noite, fazendo a síntese entre as cores negra e branca, do que se pode deduzir que se desfaz, também, o paradoxo de que se constituem tais cores. "Serás tu minha irmã?!..." 
Finalmente, interessante e inquietante é a leitura d'Os Maias. Faz-se necessário observar a representação peculiar e particular que se faz do homem são-tomense na fala de uma das personagens melhores construídas por Eça de Queiroz, João da Ega:

Ega esfregava as mãos. Sim, mas precioso! Porque essa simples forma de botas explicava todo o Portugal contemporâneo. Via-se por ali como a coisa era. Tendo abandonado o seu feitio antigo, à D. João VI, que tão bem Ihe ficava, este desgraçado Portugal decidira arranjar-se à moderna: mas, sem originalidade, sem força, sem caráter para criar um feitio seu, um feitio próprio, manda vir modelos do estrangeiro - modelos de ideias, de calças, de costumes, de leis, de arte, de cozinha... Somente, como Ihe falta o sentimento da proporção, e ao mesmo tempo o domina a impaciência de parecer muito moderno e muito civilizado - exagera o modelo, deforma-o, estraga-o até à caricatura. O figurino da bota que veio de fora era levemente estreito na ponta - imediatamente $o$ janota estica-o, aguça-o, até ao bico de alfinete. Por seu lado, o escritor lê uma página de Goncourt ou de Verlaine, em estilo preciso e cinzelado - imediatamente retorce, emaranha, desengonça a sua pobre frase, até descambar no delirante e burlesco. (...) $E$ por aí adiante assim, em todas as classes e profissões, desde o orador até ao fotografo, desde o jurisconsulto até ao sportsman... É o que sucede com os pretos já corrompidos de São Tomé, que veem os europeus de lunetas - e imaginam que nisso consiste ser civilizado e ser branco. Que fazem então? Na sua sofreguidão de progresso e de brancu- 
ra, acavalam no nariz três ou quatro lunetas, claras, defumadas, até de cor. E assim andam pela cidade, de tanga, de nariz no ar, aos tropeções, no desesperado e angustioso esforço de se equilibrarem todos estes vidros - para serem imensamente civilizados e imensamente brancos... (QUEIROZ, 2015, p. 398)

O poeta, que sai de sua terra natal, tenta se inserir nessa sociedade, caracterizada, na fala de Ega, como um Portugal sem originalidade, sem força e sem caráter para criar um feitio próprio. A crítica - no subtexto - de Eça à visão do homem de São Tomé é uma das chaves para a compreensão do ânimo de Costa Alegre vivendo em tal Portugal, corrompido, como os pretos de seu país. E consciente desse modo de pensar da metrópole.

\section{EM MOdO dE CONCLUSÃO:}

Entendidas as circunstâncias biográficas, sociais e artísticas de Costa Alegre, pode-se considerá-lo o primeiro poeta são-tomense que, tendo vivenciado sua terra natal, concebeu em sua arte os valores cultivados em seu local de origem, em forte contraste, ou mesmo oposição, aos vivenciados em desterritorialização. Não se quer lançar aqui, em absoluto, uma proposta fundacional ou de literatura marcada por uma essência nacional, mas assinalar a importância de Costa Alegre na literatura dos nascidos em São Tomé e Príncipe, como o será igualmente Marcelo da Veiga, os quais sentiram o choque de culturas por vivência direta dos ambientes são-tomense e português. Também não se pretende aqui entender que o autor, 
pela simples razão de nascer em São Tomé e Príncipe, seria o precursor, em um protossistema literário nacional - que ainda hoje espera por se delinear com traços mais nítidos.

Claude Lévi-Strauss, em seu clássico Raça e história, afirma que:

(...) Preso entre a dupla tentação de condenar experiências que o chocam afetivamente e de negar as diferenças que ele não compreende intelectualmente, o homem moderno entregou-se a toda espécie de especulações filosóficas e sociológicas para estabelecer vãos compromissos entre pólos contraditórios, e para perceber a diversidade das culturas, procurando suprimir nesta o que ela contém para ele de escandaloso e de chocante. (LEVY-STRAUSS, 2012: 20)

Com base em tal afirmação, entende-se a limitação de Cruz Magalhães ao se chocar/encontrar com Costa Alegre num país "branco" e de mentalidade colonial: é, para o prefaciador, incompreensível um jovem com alto pendor artístico em se tratando de um homem de "raça" que difere dos padrões que ele conhece e aceita.

É também preciso reconhecer, sem correr o risco de "injustiçar" o amigo de Costa Alegre que, se não fosse a sua sincera dedicação, não se poderia, hoje, no segundo decênio do século XXI, apontar o poeta dos Versos como o primeiro escritor de São Tomé e Príncipe, que verdadeiramente vivenciou, sentiu e experienciou a sua terra natal.

E não se pode olvidar o óbvio: a importância de desvincular da imagem do poeta, que era uma "fina flor do Bem", a dor 
amarga da "brutalidade descaroável de sorte para ele", fazendo-o nascer negro com alma tão branca - que deveria ser a alma de Poeta, como afirma Cruz Magalhães. O que é necessário observar, efetivamente, é um autor, mais uma vez, de forte pendor poético - interrompido pela morte precoce -, que explorou o preconceito europeu da sua época e o transformou em versos, usando as suas emoções, seus afetos e suas sensações como matéria poética - diversas vezes impregnados de fina ironia - a sua indignação, inaugurando uma poética do homem negro, ficando, dessa forma, conhecido, em Lisboa, como o poeta de São Tomé.

Caetano da Costa Alegre, tantas vezes obliterado no seu solo pátrio por Francisco José Tenreiro (que seja a ele dado o lugar devido, claro), viveu em São Tomé e Príncipe, mais precisamente na ilha de São Tomé. Viveu lá até seus 19 anos e foi estudar na metrópole, nos finais do século retrasado. Defrontou-se e confrontou-se com uma sociedade branca, racista, de mentalidade opressora. Sentiu, no entanto, a poesia correr em suas veias e encontrou nela uma via de liberdade de expressão. Foi um homem negro, que trabalhou com as palavras a antítese frisante de que nós todos, seres humanos, ora somos compostos. Não rejeitou a sua cor ou a sua nacionalidade; exaltou a beleza da mulher negra, sentiu as tristezas próprias de um jovem rejeitado pelas mulheres da metrópole, versou as suas sensações e emoções em terra estrangeira, enveredou-se pelo naturalismo - influenciado, talvez, pela sua relação com a medicina - desvelou o homem, idealizou o amor romântico, tratou das questões da cores negra e branca como material artístico. 


\section{REFERÊNCIAS BIBLIOGRÁFICAS}

COSTA ALEGRE, Caetano da. Versos. Lisboa, Imprensa Nacional-Casa da Moeda, 1994.

. Versos. São Tomé, Embaixada do Brasil em São e Príncipe e Ministério das Relações exteriores, 2012.

LEVY-STRAUSS, Claude. Raça e história. 11ed. Lisboa, Editorial Presença. 2012.

LINS, Ronaldo Lima. Nossa amiga feroz. Breve história da felicidade na expressão contemporânea. Rio de Janeiro, Rocco, 1993.

MOISÉS, Massaud. A literatura brasileira através dos textos. 29 ed. São Paulo, Cultrix, 2012.

QUEIROZ, Eça de. Os Maias. Éditions e-Books France. www. dominiopubico.org, 2015.

"Positivismo e Idealismo". Obras completas. Porto, Lello e Irmão. Vol. II., s/d.

"A decadência do riso". Obras completas. Porto, Lello e Irmão. Vol. II, s/d.

TENREIRO, Francisco José. Obra poética. Lisboa, Imprensa Nacional- Casa da Moeda, 1994.

Submissão: $30 / 02 / 2017$

Aceite: 02/10/2017 